\title{
Evaluation of the effects of the first stage of home quarantine for one week during the Covid 19 pandemic in Tehran province, Iran
}

\section{ARTICLE INFO}

\section{Article Type}

Commentary

\section{Authors}

Mehri Nejat ${ }^{1,2^{*}}, \mathrm{MD}$

Habib Rashadi MD $^{3}$

\begin{abstract}
${ }^{1}$ Faculty of Educational Sciences and Psychology, University of Tehran, Tehran, Iran..

${ }^{2}$ Sarem Fertility and Infertility Research Center (SAFIR), Sarem Women's Hospital, Iran University of Medical Sciences (IUMS), Tehran, Iran

${ }^{3}$ Tehran Orthopedic and

Physiotherapy Center.
\end{abstract}

*Corresponding Author Address: Agape Sexual Disorders Center \& Sarem Women Hospital, Basij Square, Phase 3, EkbatanTown, Tehran, Iran. Postal code: 1396956111

Phone: +98 (21) $44670888 \&$ +98 (21) 46040339

Fax: +98 (21) 44670432

mehrinejat8194@gmail.com

\section{ABSTRACT}

Commentary: In late 2019, a respiratory illness caused by the Corona virus was identified as the cause of several cases of pneumonia in Wuhan, China. Coronavirus (COVID-19), declared by the World Health Organization (WHO), is responsible for hundreds of thousands of medical records worldwide ${ }^{[1]}$. This disease has put a lot of costs on the health care system of countries around the world. Although scientists are increasingly monitoring the disease, a look at the diary statistics of the disease in Iran also shows that despite the measures taken, the disease has not yet been managed and controlled, and the statistics are increasing, if What successes have been achieved in the discussion of treatment and prevention of this disease. In the early stages of the disease, most countries used quarantine ${ }^{[2]}$ and this quarantine was also implemented in Iran. The aim of this study was to look at the effects of the first stage of home quarantine for a week during the Covid 19 pandemic in Tehran. 414 people (64\% female and 36\% male) with a mean age of 35.2199 .52 years participated in this study. Table 1 shows the demographic and psychosocial characteristics of quarantine. The study questionnaire was distributed using an electronic link

https://docs.google.com/forms/d/13fnHSLAGq74Nlv9141GfcOa2fia8zBC_PEWt6BDVsAY This questionnaire was distributed through social media for one week in Tehran province from 2020 April 8 . The questionnaire included a form related to demographic characteristics and a form related to psychological indicators related to quarantine and coronation.

Keywords: COVID-19; Pandemic; Home quarantine; Mental disorders; Health; Economy; Pneumonia.

\section{Article History}

Received: April 25, 2020

Accepted: May 27, 2020

e Published: March 04, 2021

Copyright $($ 2021, ASP Ins. This open-access article is published under the terms of the Creative Commons Attribution-Noncommercial 4.0 International License which permits Share (copy and distribute the material in any medium or format) and Adapt (remix, transform, and build 
كليد وازٔهها: كوويد-9 ا؛ پاندمى؛ قرنطينه خانكى؛ اختلالات روانى؛ بهداشت؛ اقتصاد؛ رينومونى

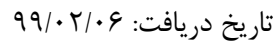

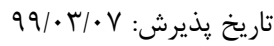

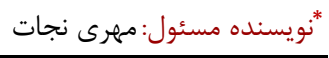

داده ها و نتيجه كيرى

\begin{tabular}{|c|c|c|c|c|c|}
\hline درصد & تعداد & متغير & درصد & تعداد & متغير \\
\hline & & ناشى از كرونا مالى & & & تحصيلات \\
\hline$\Delta 9 / T$ & TFQ & بله & $19 / \pi$ & $9 \mathrm{~V}$ & زير ديِلم، دييلمم و \\
\hline \multirow[t]{2}{*}{$r \cdot / \Lambda$} & 199 & خير & $F Y / Q$ & $19 \mathrm{~V}$ & كارشناسى \\
\hline & & اعصاب و و روان بيمارى & $r 1 / r$ & 119 & كارشناسى ارشد \\
\hline ir & $\Delta F$ & بله & $1 \cdot 11$ & fr & دكترى \\
\hline \multirow[t]{2}{*}{$\wedge \vee$} & rq. & خير & & & وضعيت تاهل \\
\hline & & سابقه مصرف & $r \varepsilon / 1$ & $1 \cdot 1$ & مجرد \\
\hline $11 / 1$ & is & مشروبات الكلى & GN/9 & rAF & متاهل \\
\hline $\mid r / \Lambda$ & $\Delta V$ & سيخار & $\Delta / r$ & Tt & جدا شده و بيوه \\
\hline$\cdot / V$ & $r$ & مواد مخدر & & & خانواده كه باهم در اعضاى \\
\hline $10 / \Delta$ & gf & 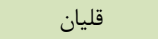 & $r / 9$ & 19 & 1 \\
\hline \multirow[t]{2}{*}{$F V / F$} & $r \cdot \Lambda$ & هيجֶدام & 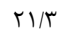 & $\Lambda$ & r \\
\hline & & شكوى به كرون افراد & T\&/G & 11. & $r$ \\
\hline $4 / 9$ & 19 & بله & $r T / l$ & אזו & f \\
\hline \multirow[t]{2}{*}{$9 \Delta / \mathcal{F}$} & $r 9 \Delta$ & خير & $1 \cdot / 4$ & Ft & $\Delta$ \\
\hline & & خانواده به كرونا اعضاى & $\Delta / \Lambda$ & rF & 9و بالاتر \\
\hline $9 T / T$ & 11 & بله & & & 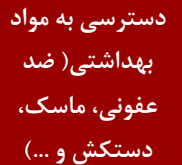 \\
\hline \multirow[t]{2}{*}{$N / \Lambda$} & $r \cdot r$ & خير & $\Lambda T / F$ & rᄉF & بله \\
\hline & & مربويافت اخبار & $\mid V / G$ & $V \mu$ & خير \\
\hline
\end{tabular}

ارزيابى اثرات مرحله اول قرنطينه خانگى به مدت يك هفته طى ياندمى كوويد 19 در استان تهران، ايران

' لد دانشكده علوم تربيتى و روانشناسى دانشعاه تهران، تهران، ايران.

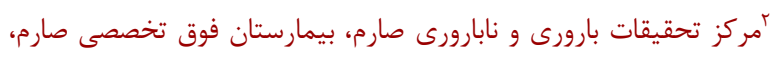
دانشعاه علوم يزشكى ايران، تهران، ايران.

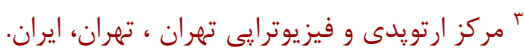

جكيده تفسير: در اواخر سال 19 • + يك بيمارى تنفسى ناشى از ويروس كرونا به

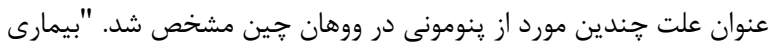

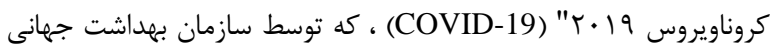

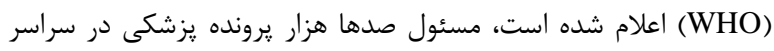

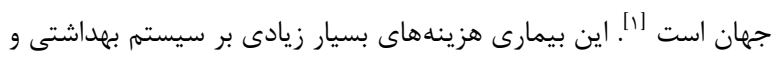

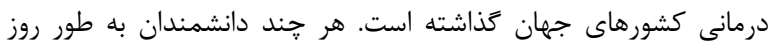

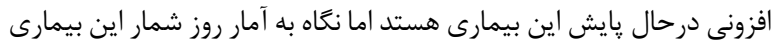

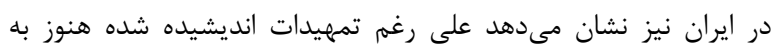

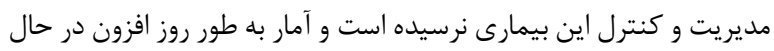

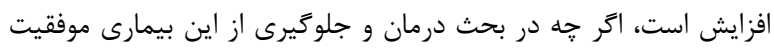

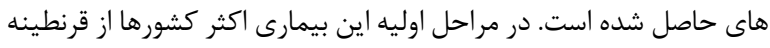

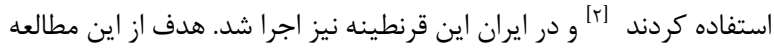

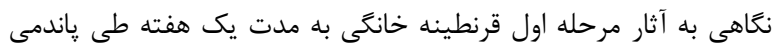

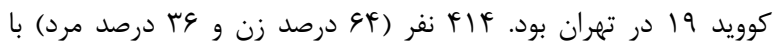

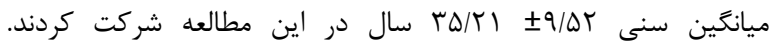

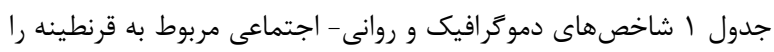

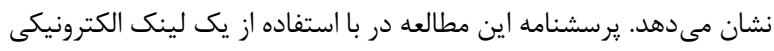
https://docs.google.com/forms/d/13fnHSLAGq74Nlv9141Gf) (cOa2fia8zBC PEWt6BDVsAY توزيع شد. اين يرسشنامه از تاريخ •

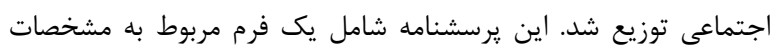

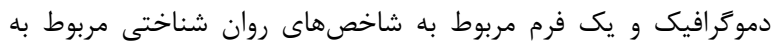
قرنطينه و كرونا بود. 


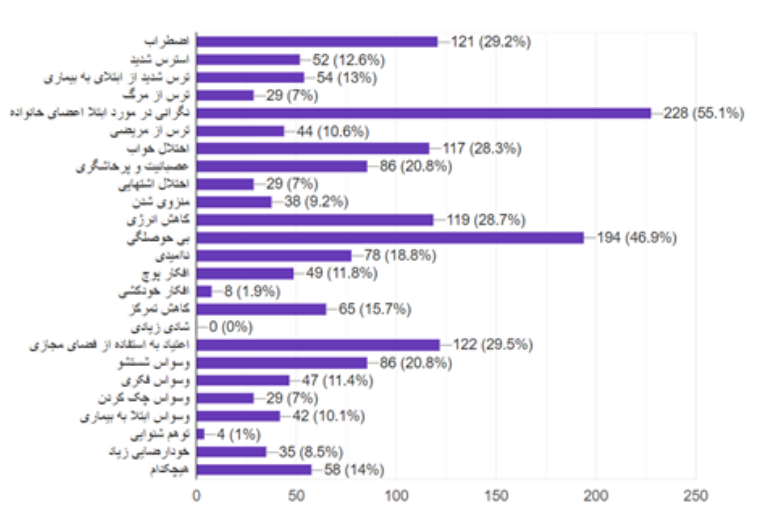

شكل ا: حالات و علايم روان شناختى در طى هفته اول قرنطينه بر اثر كرونا

روش همبستكى ييرسون نشان داد كه ارتباط مثبت و معنى دارى بين

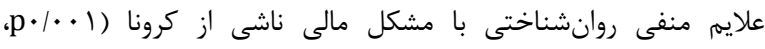
مي

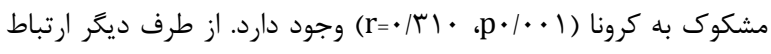

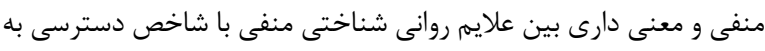

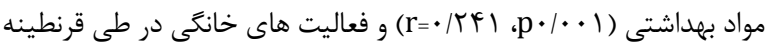

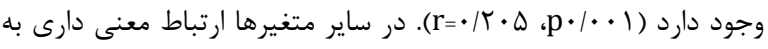

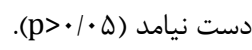
همانطور كه نتايج نشان داد بهبود دسترسى به به مواد و اقلام بهامداشتى و

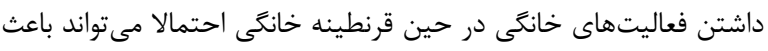

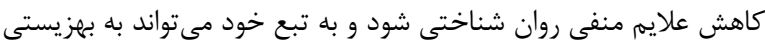

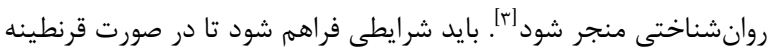

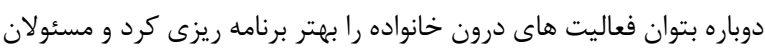

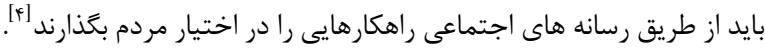

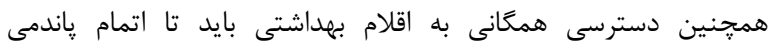

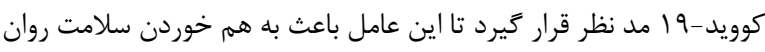

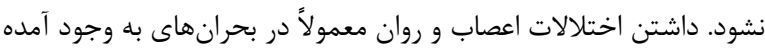

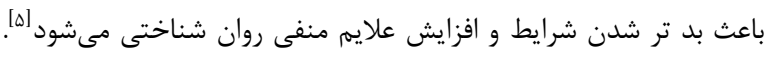

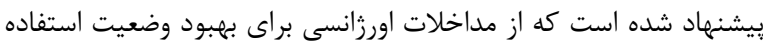

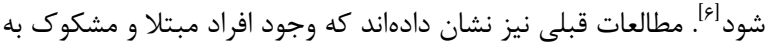

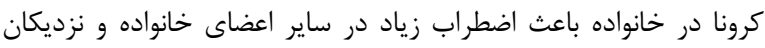

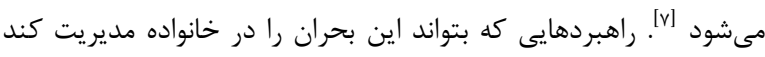

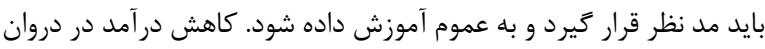

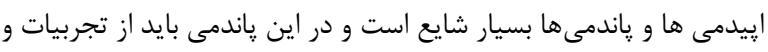
بحران هاى اقتصادى كذاشته استفاده شود تا اثرات آن در خانواده ها كاهش

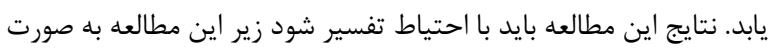

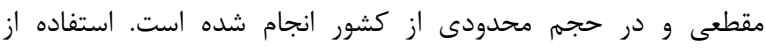

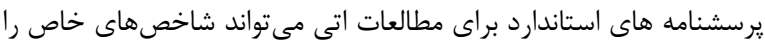

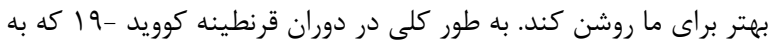

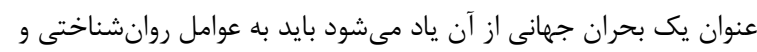

\begin{tabular}{|c|c|c|c|c|c|}
\hline $9 N / 9$ & TAF & تلويزيون & & & تهيه مواد اوليه \\
\hline$r V / I$ & $11 \%$ & ماهواره & $11 / 4$ & rrv & حضورى \\
\hline$r_{4}$ & $14 q$ & خبر كدارى هاى & $9 / \Delta$ & TV & تلفنى \\
\hline$\Delta F / q$ & $T r V$ & شبكه هاى & $1 \pi / \Lambda$ & $\Delta V$ & اينترنتى \\
\hline \multirow[t]{2}{*}{$r \cdot / r$} & $I T V$ & افراد خانواده و & $r \mid / Q$ & 19 & خريد شخص ديكر \\
\hline & & فاليً فرنى در & & & مربك كردن اخبار \\
\hline ^. & ו & ديدن فيلم و & Tr/I & rזו & 1 \\
\hline$\Delta T / F$ & rIV & ورزش & $r T / V$ & 91 & r \\
\hline$r \Lambda$ & 119 & همراه خانوان وقت به & 10 & Gr & $r$ \\
\hline $89 / 1$ & TAS & اينترنت و فضاى & $\Delta / \Lambda$ & $T^{F}$ & r \\
\hline \multirow[t]{2}{*}{$s 4 / 0$} & reV & موسيقى & $N / \Delta$ & ro & $\Delta$ \\
\hline & & جنسى رابطه & 1.14 & Fr & 9 و بالاتر \\
\hline $9 D / \Lambda$ & rmo & بله & & & رابطه با فرزندان \\
\hline \multirow[t]{2}{*}{$r F / T$} & ITr & خير & $\mid V / F$ & VT & بسيار عالى \\
\hline & & نياز در روزهاى & $T V / T$ & $11 \%$ & خوب \\
\hline$\Delta r / 1$ & Tr. & مسايل مربوط به & $r / q$ & rq & متوسط \\
\hline$r 1 / 9$ & rT & شمايل مربوط به مهار & $1 / 9$ & $\wedge$ & بد \\
\hline $9 \Delta / \Delta$ & rrI & ساير & $F \& / T$ & $1 M$ & فرزندى ندارم \\
\hline
\end{tabular}

جدول ا: شاخص هاى دموكرافيك و روانى -جتماعى مربوط به قرنطينه

همجنين در شكل | وضعيت حالات روان شناختى كزارش شده است.

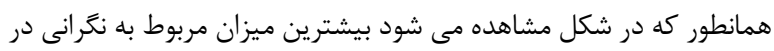

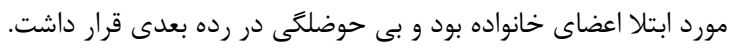


6. Ho CS, Chee CY, Ho RC. Mental health strategies to combat the psychological impact of COVID-19 beyond paranoia and panic. Ann Acad Med Singapore. 2020 Jan 1;49(1):1-3.

7. Zhao H, He X, Fan G, Li L, Huang Q, Qiu Q, Kang Z, Du T, Han L, Ding L, Xu H. COVID-19 infection outbreak increases anxiety level of general public in China: involved mechanisms and influencing factors. Journal of affective disorders. 2020 Nov 1;276:446-52.

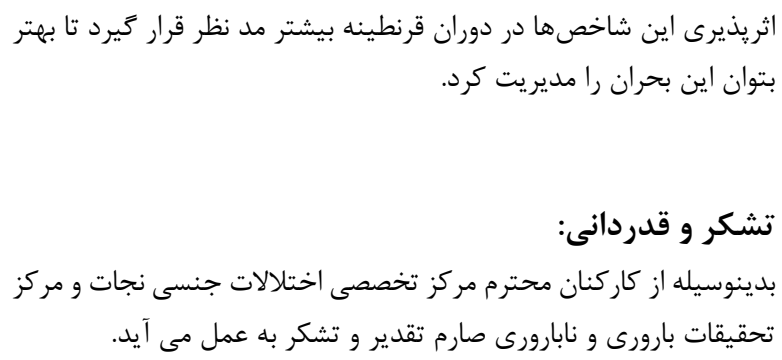

1. World Health Organization. Coronavirus disease 2019 (COVID-19): situation report, 72.

2. Bedford J, Enria D, Giesecke J, Heymann DL, Ihekweazu C, Kobinger G, Lane HC, Memish Z, Oh MD, Schuchat A, Ungchusak K. COVID-19: towards controlling of a pandemic. The Lancet. 2020 Mar 28;395(10229):1015-8.

3. Feng S, Shen C, Xia N, Song W, Fan M, Cowling BJ. Rational use of face masks in the COVID-19 pandemic. The Lancet Respiratory Medicine. 2020 May 1;8(5):434-6.

4. Wang G, Zhang Y, Zhao J, Zhang J, Jiang F. Mitigate the effects of home confinement on children during the COVID-19 outbreak. The Lancet. 2020 Mar 21;395(10228):945-7.

5. Rajkumar RP. COVID-19 and mental health: A review of the existing literature. Asian journal of psychiatry. 2020 Apr 10:102066. 